\title{
Comparison of the stress-strain state of the reinforced concrete structure under various mathematical models of concrete
}

\author{
Dmitriy Sidorov and Vladimir Dorozhinskiy* \\ Moscow State University of Civil Engineering, Yaroslavskoe shosse, 26, Moscow, 129337, Russia
}

\begin{abstract}
Nowadays, reinforced concrete structures are most often used as load-bearing elements of buildings and structures. In the case of alternating loads such as seismic action, there is accumulation of residual plastic deformations in the concrete structures, which leads to a significant complication in the calculation of structures by "standard" methods. For such problems, it is advisable to use computational complexes in which mathematical models of structural materials are implemented, which allow to describe the work of concrete and reinforcing bars for various types of impacts more properly. However, when applying such methods, the results obtained should not contradict the requirements of the existing regulatory documents, which, in the first place, the structural engineer should be guided by. Before solving more complex problems, the applied methods should be verified and analyzed for fairly simple structures and types of loads.
\end{abstract}

\section{Problem setting}

Let us consider, for example, the calculation of a reinforced concrete pyramidal column. The structure has a foundation in the form of a $3000 \times 2400 \mathrm{~mm}$ rectangle and a cap in the form of a $1000 \times 1000 \mathrm{~mm}$ square (Figure 1). The height of the column is $11.5 \mathrm{~m}$.

The main material is B35 concrete. The column is reinforced with A500C longitudinal principal reinforcing bars with variable pitch and number of rods along the height, transverse reinforcing bars are made of A500C and A240 closed stirrup and "pins".

In the upper level, the structure is acted upon by the longitudinal compressive force and by two orthogonal horizontal forces which cause a combined strength in the variable section of the column: torsional compression and bending in two planes.

\footnotetext{
* Corresponding author: dorozhinski@ mail.ru
} 

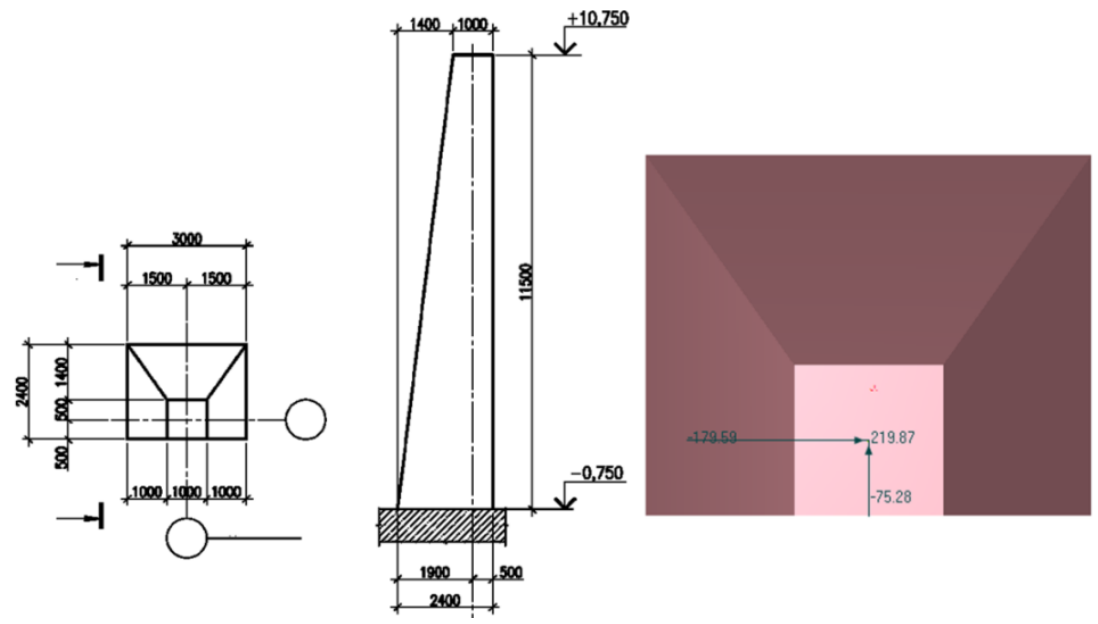

Fig. 1. General view of the pyramidal column and the scheme of applied loads $\left(\mathrm{N} \cdot 10^{4}\right)$.

The calculations were performed taking into account the geometric and physical nonlinearities in the Ansys/LS-Dyna PC, which allows using explicit and implicit formulations of the finite element method. Volumetric finite elements were used for concrete modeling, rod elements were used to model bar reinforcement (Figure 2).
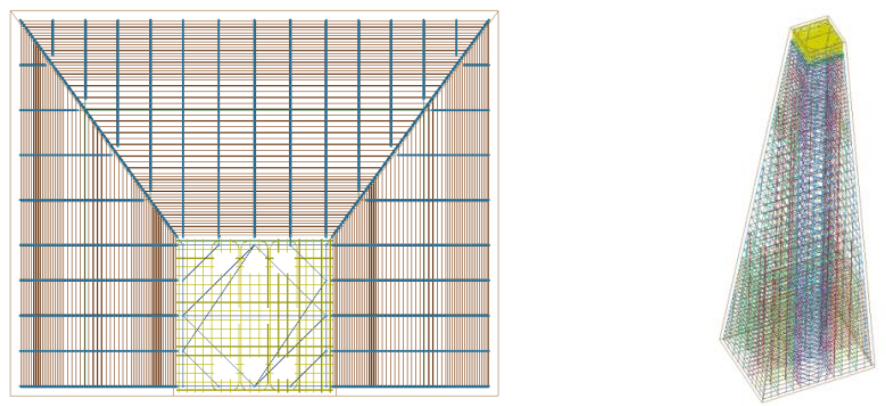

Fig. 2. Design model of a column with a specified reinforcement.

Nonlinear behavior of reinforcing steel was described by a two-line diagram, according to the current regulatory documents. To take into account the nonlinear behavior of the column concrete various mathematical models of the material were used:

1. As a diagram of the " $\sigma-\varepsilon "$ concrete behavior, a three-line diagram is taken according to the current regulatory documents (Figure 3) [1-3].

2. CSCM model (Continuous Surface Cap Model) takes into account the decrease in the modulus of deformation and strength of concrete in the zone of crack formation [1-4].

3. Winfrith model allows for determination of the zone and the amount of crack opening $[5]$.

In the CSCM model stress invariants are defined in terms of the deviatoric stress tensor $S_{i j}$ and pressure $P$ as follows:

$$
I_{1}=3 P, I_{2}=\frac{1}{2} S_{i j} S_{i j}, I_{2}=\frac{1}{3} S_{i j} S_{j k} S_{k i} \text {. }
$$

The three invariant yield function is based on these invariants and cap hardening parameter $\kappa$ :

$$
f\left(I_{1}, I_{2}, I_{3}, \kappa\right)=I_{2}-\Re^{2} F_{f}^{2} F_{c} .
$$


Here $F_{f}$ is the shear failure surface, $F_{c}$ is the hardening cap, $\Re$ is the Rubin threeinvariant reduction factor. The cap hardening parameter $\kappa$ is the value of the pressure invariant at the intersection of the cap and shear surfces.

The Winfrith concrete model is based on the Ottosen plasticity model, where:

$$
\lambda=\left\{\begin{array}{c}
f\left(I_{1}, I_{2}, I_{3}\right)=a I_{1}+\lambda \sqrt{I_{2}}+b I_{3}-1, \\
k_{1} \cos \left[\frac{1}{3} \cos ^{-1}\left(k_{2} \cos (3 \theta)\right)\right], \cos (3 \theta) \geq 0 \\
k_{1} \cos \left[\frac{\pi}{3}-\frac{1}{3} \cos ^{-1}\left(-k_{2} \cos (3 \theta)\right)\right], \cos (3 \theta) \leq 0
\end{array}, \cos (3 \theta)=\frac{3 \sqrt{3}}{2} \frac{I_{3}}{I_{2}^{\frac{3}{2}}} .\right.
$$

The four parameters of this model $\left(a, b, k_{1}\right.$ and $\left.k_{2}\right)$ are determined from tension and compression tests, $I-$ stress tensor invariant.

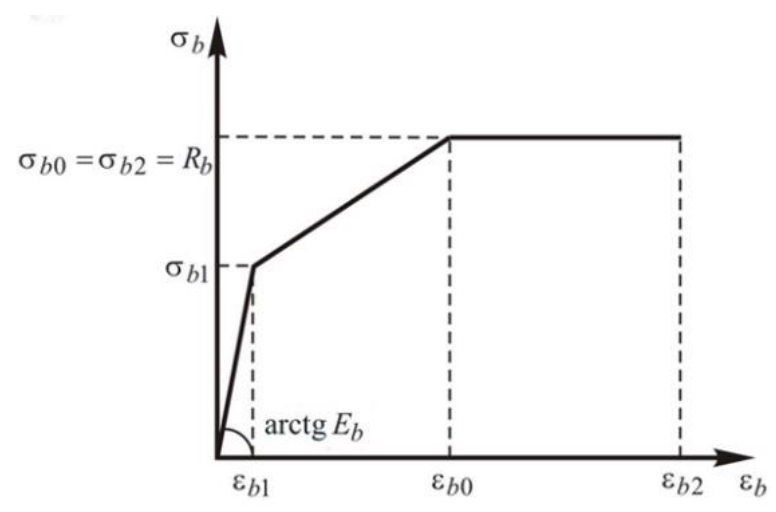

Fig. 3. Three-line diagram of the concrete behavior.

\section{Main results}

Comparison of the calculation results was carried out according to the following parameters: horizontal displacements of the top of the column and the stress-strain state of the reinforcing bars and concrete. Some of the data obtained are given below.

Figures 4-6 show the isofields of horizontal displacements, stress intensity in concrete and longitudinal reinforcing bars for the normative model. Figure 7 shows the pattern of cracks in concrete for the Winfrith model.

The figures show that the most heavily loaded zones along the column height are cross sections of inclined faces, in which the number of longitudinal reinforcing bars varies. As a consequence, the greatest tensile stresses appear and the greatest crack opening occurs in these points of the concrete. The stresses in the reinforcing bars in these zones also have the highest values. 

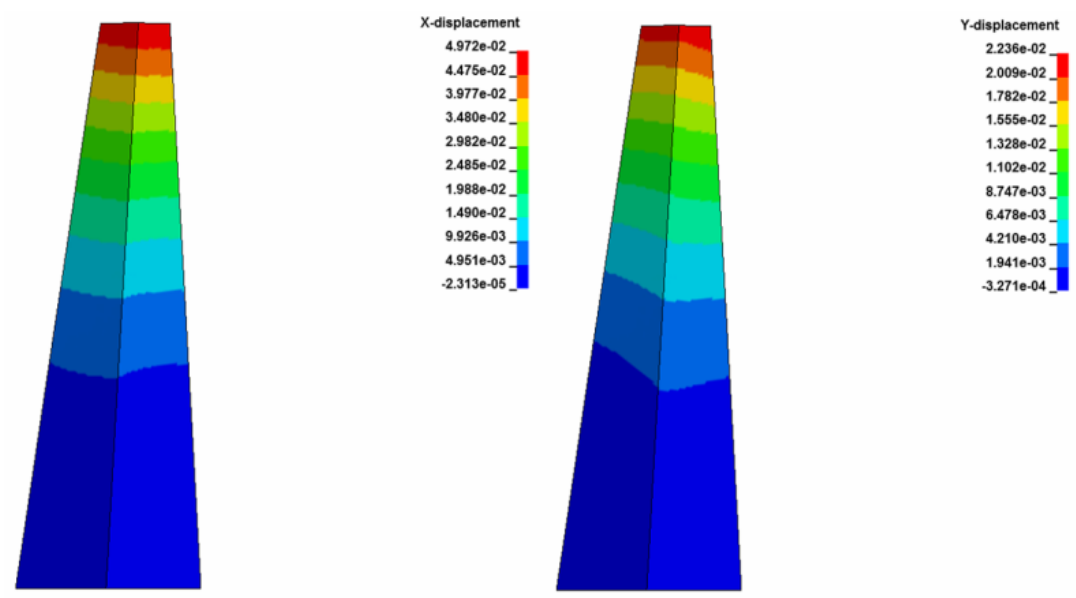

Fig. 4. Horizontal displacement along the $\mathrm{X}$ (left) and $\mathrm{Y}$ (right) axes, $\mathrm{m}$.

\begin{abstract}
Contours of Effective Stress $(\mathrm{v}-\mathrm{m})$
min=133683, at elemm 22922 $\min =133683$, at elemu\# 22922
$\max =1.5178 \mathrm{e}+07$, at elem\# 10967
\end{abstract}

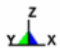

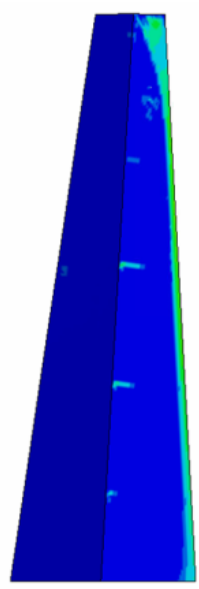

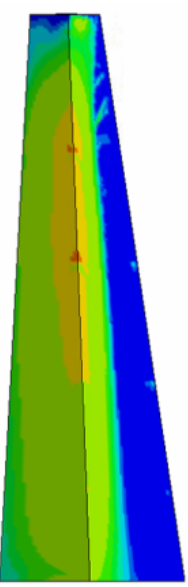

Fig. 5. Stress intensity in concrete, $\mathrm{Pa}$.

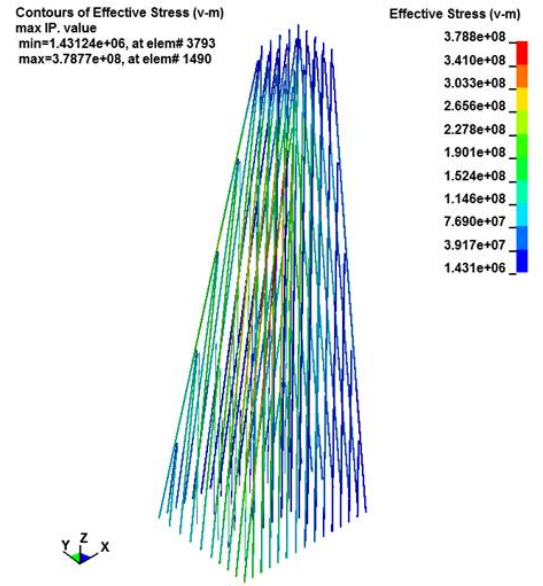

Fig. 6. Stress intensity in reinforcing bar, Pa.
$\stackrel{L}{x} x_{x}$

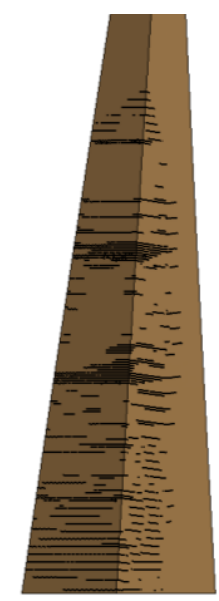

Fig. 7. Crack formation scheme. 
Table 1 shows the results of comparison of controlled parameters for the models considered.

Table 1. Key results of calculations.

\begin{tabular}{|c|c|c|c|c|}
\hline \multirow{2}{*}{ No. } & \multirow{2}{*}{ Parameter } & \multicolumn{3}{|c|}{ Model type } \\
\hline & & Normative model & CSCM & Winfrith \\
\hline 1 & $\begin{array}{c}\text { Displacements: } \\
\text { - along the } \mathrm{X} \text { axis, } \mathrm{m} \\
\text { - along the } \mathrm{Y} \text { axis, } \mathrm{m} \\
\text { - along the } \mathrm{Y} \text { axis, } \mathrm{m}\end{array}$ & $\begin{array}{c}0.0497 \\
0.0224 \\
0.011 \\
\end{array}$ & $\begin{array}{c}0.0735 \\
0.0251 \\
0.016\end{array}$ & $\begin{array}{c}0.062 \\
0.0222 \\
0.014\end{array}$ \\
\hline 2 & $\begin{array}{l}\text { Stress intensity in longitudinal } \\
\text { reinforcing bar, } \mathrm{Pa}\end{array}$ & $379 \cdot 10^{6}$ & $435 \cdot 10^{6}$ & $435 \cdot 10^{6}$ \\
\hline 3 & Stress intensity in concrete, $\mathrm{Pa}$ & $14.9 \cdot 10^{6}$ & $25.4 \cdot 10^{6}$ & $25.9 \cdot 10^{6}$ \\
\hline 4 & $\begin{array}{l}\text { Tensile/compressive stresses in } \\
\text { concrete, } \mathrm{Pa}\end{array}$ & $\begin{array}{c}1.6 \cdot 10^{6} \% \\
-14.9 \cdot 10^{6}\end{array}$ & $\begin{array}{c}1.53 \cdot 10^{6} \% \\
-25.4 \cdot 10^{6}\end{array}$ & $\begin{array}{c}2.3 \cdot 10^{6} \% \\
-25.9 \cdot 10^{6}\end{array}$ \\
\hline
\end{tabular}

\section{Conclusions}

Analyzing the carried out researches and the data received, it is possible to draw the following conclusions:

1. The results of calculations for the models considered qualitatively coincide with the normative model for displacements and the nature of stress distribution in the structure. The difference in the values of the maximum displacements and stresses is explained by a different formulation in determining the rigidity of the elements.

2. When using the normative model, as the stresses and deformations of the concrete reach their limiting values, the finite elements are completely excluded from work in the zones of crack formation. This leads to a decrease in the load-bearing capacity of the structure due to the reduction in cross-sectional dimensions, which does not correspond to the actual work of reinforced concrete. More modern concrete models, in which the modulus of elasticity is recalculated during formation of cracks, lack such a disadvantage. Therefore, in carrying out further studies and calculations of structures, including seismic actions, it is advisable to use the CSCM and Winfrith models to obtain a more adequate picture of the operation of load-bearing elements.

This study was performed with the support of the RF Ministry of Education and Science, grant \#7.1524.2017/4.6.

\section{References}

1. O. Mkrtychev, D. Sidorov, S. Bulushev MATEC WoC 117, 00123 (2017)

2. O. Mkrtychev, M. Andreev MATEC WoC 196, 01029 (2018)

3. O. Mkrtychev, M. Busalova, V. Dorozhinskiy MATEC WoC 117, 00124 (2017)

4. US Department of Transportation. Federal Highway Administration. Evaluation of LSDYNA Concrete. Material Model 159. FHWA-HRT-05-063, 190 (2007)

5. L. Schwer. 8th European LS-DYNA Users Conference (2011) 